\title{
A LECTURE EXPERIMENT ILLUSTRATIVE OF VALENCE.
}

BX LAUNCELOT W. ANDREWS, Professor of Chemistry, State University of Iowa.

The experiment about to be described is not new in principle, but the simple form of apparatus required and certain features of the manipulations recommended and of the material employed seem to justify publication. The foundation idea is to measure the hydrogen evolved from equal atomic proportions of an univalent, a bivalent and a tervalent metal, respectively, on solution in acid. Sodium, magnesium and aluminium are selected as the metals. The apparatus is represented in the accompanying figure. $A$ and $B$ are two glass tubes about $35 \mathrm{~cm}$. in length and about $1.5 \mathrm{~cm}$. in diameter. They are closed at the bottom by perforated rubber stoppers and are connected together by a short piece of narrow bent glass tubing, as shown.

The measuring tube $A$ is drawn down at the top to $6 \mathrm{~mm}$. diameter, while the top of $B$ is open. A tube $C$ of $6 \mathrm{~mm}$. diameter is connected to the top of $A$ by a short length of rather thin rubber tubing. When the tube $C$ is bent over to one side it may be held in the position shown in the figure by a loop of wire, the connection being nicked together at $M$. The glass tube with rubber connection at $X$, which is elosed by a common brass wire pinch-eock, is used for emptying the liquid out of the system and for equalizing the height of liquid in the tubes $A$ and $B$.

The apparatus is made and used in triplicate.

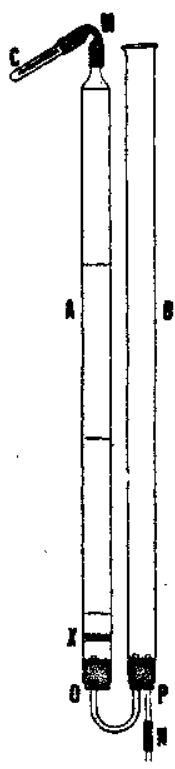
The manipulations are as follows: Place in the tube $C$ a bit of aluminum wire weighing $27 \mathrm{mg}$. (respectively, $24 \mathrm{mg}$. of $\mathrm{Mg}$ or 23 of Мa), attach it to $A$ and hook it over, the tubes $A$ and $B$ having previously been filled with hydrochloric acid of about 1.14 specific gravity. Slip a rubber ring over $A$ to mark the meniscus of the acid solution, of course after equating the level. 
When everything is ready, remove the wire hook, allowing $C$ to spring into the upright position, when the weighed aluminium will fall into the acid and dissolve, the pinch-cock at $N$ being opened at this time to allow the excess of acid to escape. Since bubbles of gas might be carried over with the acid if the aluminium were permitted to fall to the bottom of the tube, a slice of cork is first inserted at $X$, which, acting as a shelf, holds the metal. This cork has four or five small diagonal notches cut around its periphery with a sharp knife, thus permitting the acid to pass, but not the wire. When the metal has dissolved the hydrogen in $A$ will be found to measure nearly $35 \mathrm{cc}$.

In the second identical apparatus, in which exactly $24 \mathrm{mg}$. of bright, freshly scraped magnesium band is placed, it is desirable to use a weaker hydrochloric acid, that of 1.05 specific gravity being suitable.

In the third set, sodium is employed and the technique of the weighing and introduction of this metal demands a word of explanation. It is especially simple if a sodium press is at hand capable of producing sodium wire of about $1 . \mathrm{mm}$. diameter. First, ascertain what length of wire weighs $23 \mathrm{mgs}$. by running from the press about $10 \mathrm{~cm}$. of sodium wire into a weighed glass tube of 3 or $4 \mathrm{~mm}$. diameter and weighing again. Suppose, to take an actual case, that it is found that just $25 \mathrm{~mm}$. of this wire weighs $23 \mathrm{mg}$. Prepare a glass tube of $2 \mathrm{~mm}$. internal diameter and about $40 \mathrm{~mm}$. long and mark it exactly $25 \mathrm{~mm}$. from one end. Squeeze sodium from the press and cut it off close to the nozzle; now hold the tube against the orifice, squeeze out sodium till the wire reaches the mark on the tube, cut it off with a penknife and at once introduce the glass tube with the sodium in it into. the tube $C$.

If no sodium press is available the following method can be used: Select a piece of glass tubing of a little less than one millimeter internal diameter and about eight inches long. Melt a lump of sodium in a dry test tube and dip the narrow glass tube into it, and with the mouth draw up the melted metal several inches into it, where it is permitted to solidify. With a 
sharp file cut off a definite length, say $50 \mathrm{~mm}$., of the tube and divide the contained sodium with a knife. Weigh the piece so removed, throw it into water and then weigh the glass after washing and drying. This gives you the weight of sodium in $50 \mathrm{~mm}$. of the tube. Now cut off in the same manner the length calculated to contain $23 \mathrm{mg}$. of sodium and put it in the tube $A$. Either of these methods of getting a determinate weight of sodium is much easier and also more accurate than it sounds. There is no trouble in obtaining an amount within $0.5 \mathrm{mg}$. of that desired. The glass tube falls with the sodium wire into the water with which the tube $A$ is charged, the glass preventing the sodium from sticking on the way down. The three sets of apparatus must be prepared before the lecture and set up side by side in a suitable holder. The actual experinent does not require more than six minutes, and the rolumes of gas evolved are in the ratio of $1: 2: 3$ as accurately as can be desired or expected in such an experiment. It would be well if the acid could be colored by some dye, so as to be more easily visible in a large lecture room; in a small one no such device is needed, but all dyes tried are bleached, either by the aluminum or by the sodium.

\section{OBSERVATIONAL WORK CONNECTED WITH ALMANAC DATA (II).}

BY G. W. MYERS,

College of Education, The University of Chicago.

Like all other laws of nature the law of change of length of the day, discussed in my November paper (page 281), derives its chief value from its relations to other natural laws. It is important that the pupil should get cleariy in mind not merely that the length of the time the sun is above the horizon varies from month to month for the same latitude and from latitude to latitude for the same month; but he must also be led to realize, in this connection, the effect of the varying slant of the sun's rays. A very sitisfactory way of approaching this question with a high schors class is by the aid of an instrument like the one shown in the 